\title{
The Glucagon-Like Peptide-1 Receptor Agonist Exendin-4 Inhibits Lipopolysaccharide-Induced Osteoclast Formation and Bone Resorption via Inhibition of TNF- $\alpha$ Expression in Macrophages
}

\author{
Wei-Ren Shen, Keisuke Kimura, Masahiko Ishida, Haruki Sugisawa, Akiko Kishikawa, \\ Kazuhiro Shima, Saika Ogawa, Jiawei Qi, and Hideki Kitaura
} Division of Orthodontics and Dentofacial Orthopedics, Department of Translational Medicine, Tohoku University Graduate School of
Dentistry, 4-1 Seiryo-machi, Aoba-ku, Sendai 980-8575, Japan

Correspondence should be addressed to Hideki Kitaura; hkitaura@m.tohoku.ac.jp

Received 27 July 2017; Accepted 24 January 2018; Published 13 March 2018

Academic Editor: Hao Liu

Copyright (C) 2018 Wei-Ren Shen et al. This is an open access article distributed under the Creative Commons Attribution License, which permits unrestricted use, distribution, and reproduction in any medium, provided the original work is properly cited.

\begin{abstract}
Glucagon-like peptide-1 (GLP-1) receptor agonists are an effective treatment approach for type 2 diabetes. Recently, antiinflammatory effects of GLP-1 receptor agonists have also been reported. Lipopolysaccharide (LPS) induces inflammation and osteoclast formation. In this study, we investigated the effect of exendin-4, a widely used GLP-1 receptor agonist, in LPS-induced osteoclast formation and bone resorption. LPS with or without exendin-4 was administered on mouse calvariae by daily subcutaneous injection. The number of osteoclasts, the ratio of bone resorption pits, and the level of C-terminal cross-linked telopeptide of type I collagen (CTX) were significantly lower in LPS- and exendin-4-coadministered mice than in mice administered with LPS alone. RANKL and TNF- $\alpha$ mRNA expression levels were lower in the exendin-4- and LPScoadministered group than in the LPS-administered group. Our in vitro results showed no direct effects of exendin-4 on RANKL-induced osteoclast formation, TNF- $\alpha$-induced osteoclast formation, or LPS-induced RANKL expression in stromal cells. Conversely, TNF- $\alpha$ mRNA expression was inhibited in the exendin-4- and LPS-cotreated macrophages compared with cells treated with LPS alone. These results indicate that the GLP-1 receptor agonist exendin-4 may inhibit LPS-induced osteoclast formation and bone resorption by inhibiting LPS-induced TNF- $\alpha$ production in macrophages.
\end{abstract}

\section{Introduction}

The prevalence of type 2 diabetes mellitus is increasing worldwide, and the condition has become a major public health problem. Individuals with type 2 diabetes have been shown to have a higher risk of bone fracture compared with individuals without type 2 diabetes [1]. This higher risk might be associated with the pathobiology of type 2 diabetes itself; however, the underlying mechanisms remain unclear [2]. Additionally, increased bone fracture risk is a consequence of therapeutic regimen used to treat hyperglycemia [3]. For example, patients treated with thiazolidinediones and human recombinant insulin have been shown to have an increased bone fracture risk [4-7]. Conversely, treatment with metformin is related to decreased bone fracture risk [8].
Osteoclast recruitment is crucial to the pathogenesis of diseases involving bone erosion, such as rheumatoid arthritis [9]. Osteoclasts derived from bone marrow cells are responsible for bone resorption and remodeling [10]. Receptor activator of NF-kB ligand (RANKL) and macrophage colony-stimulating factor (M-CSF) are two key factors required for osteoclast formation and activation [11]. Independent of RANKL, tumor necrosis factor- (TNF-) $\alpha$ has also been reported to induce osteoclast formation in vitro [12-14] and in vivo $[15,16]$.

Lipopolysaccharide (LPS) strongly induces inflammation and inflammatory bone loss [17-21]. LPS has also been found to induce production of proinflammatory cytokines, such as TNF- $\alpha$, from macrophages or other cells at the site of inflammation $[22,23]$. Such proinflammatory cytokines have been reported to be involved in LPS-induced osteoclast 
formation and bone destruction in in vivo and in vitro studies [18, 24-27]. Additionally, LPS can stimulate osteoblasts to produce or secrete RANKL [28].

Glucagon-like peptide-1 (GLP-1), an intestinal hormone, plays important roles in blood glucose control and proliferation of pancreatic islet $\beta$-cells $[29,30]$. GLP-1 receptordeficient mice were reported to exhibit osteopenia and increased osteoclast formation, suggesting that the GLP-1 signaling has an inhibitory effect of bone resorption on bone metabolism [31]. An anabolic effect of GLP-1 on bone metabolism has also been proposed. GLP-1 receptor activation has been shown to induce bone formation in streptozotocininduced diabetic and fructose-stimulated insulin-resistant rats [32].

It has been reported that patients with type 2 diabetes have high risk of bone fracture $[1,2]$. Furthermore, antidiabetic medicines such as thiazolidinediones may further promote bone resorption and increase fracture risk [33-35]. However, a recent meta-analysis has reported that GLP-1 receptor agonist treatment does not affect fracture risk in type 2 diabetic patients [36, 37].

The anabolic and antiresorptive effects of GLP-1 receptor suggest that GLP-1 receptor signaling may be a promising therapeutic target for osteoporosis or other osteolytic bone diseases; such a therapeutic approach would be facilitated by the fact that the first commercially available GLP-1 receptor agonist, exendin-4, has already been approved for the treatment of diabetes for over 10 years [38]. Exendin4 shares similar structural and functional properties to GLP-1 but is resistant to the degradation by dipeptidyl peptidase-IV, which can degrade GLP-1 immediately in the blood [39]. The extended half-life, improved pharmacokinetics, and high potency of exendin-4 make it suitable for clinical use [39-41].

In the present study, we investigated the effects of exendin-4 on LPS-induced osteoclast formation and bone remodeling in mice.

\section{Materials and Methods}

2.1. Animals and Reagents. Eight- to ten-week-old male C57BL6/J mice were obtained from CLEA Japan (Tokyo, Japan) and maintained at our animal facility. All animal care and experiments were conducted according to Tohoku University rules and regulations. Four mice were randomly assigned to each experimental group. Both Escherichia coli LPS and exendin- 4 were purchased from Sigma-Aldrich (St. Louis, MO).

2.2. Histological Analysis. A previous in vivo study demonstrated that daily subcutaneous injections of $100 \mu \mathrm{g}$ LPS to mouse calvariae for 5 days effectively induced osteoclast formation [42]. Therefore, we followed the same protocol, dose, and LPS administration period in this study. The mice were divided into four experimental groups and subjected to daily subcutaneous injections on the calvaria with phosphatebuffered saline (PBS, negative control group), LPS alone $(100 \mu \mathrm{g} /$ day, positive control group), LPS (100 $\mathrm{g} /$ day) and exendin-4 $(20 \mu \mathrm{g} / \mathrm{day})$, and exendin-4 alone $(20 \mu \mathrm{g} / \mathrm{day})$ for 5 days. All mice calvariae were excised immediately after sacrifice on the sixth day. The calvariae were fixed in $4 \%$ PBS-buffered formaldehyde at $4^{\circ} \mathrm{C}$ overnight and then demineralized with $14 \%$ ethylenediaminetetraacetic acid (EDTA) at room temperature for three days. Each calvaria was cut into three pieces perpendicular to the sagittal suture. Samples were then embedded in paraffin and cut into $5 \mu \mathrm{m}$ sections using a microtome. The paraffin sections were stained with tartrate-resistant acid phosphatase (TRAP) solution prepared by mixing acetate buffer ( $\mathrm{pH}$ 5.0), naphthol AS-MX phosphate (Sigma Chemical, St. Louis, MO, USA), Fast Red Violet LB Salt (Sigma), and $50 \mathrm{mM}$ sodium tartrate. The sections were counterstained with hematoxylin. Osteoclasts were defined in this study as TRAP-positive cells with three or more nuclei. We counted the number of osteoclasts only at the suture mesenchyme of the sagittal suture in all slides according to the method in our previous work [43].

\subsection{Preparation of Osteoclast Precursors for Osteoclastogenesis.} To isolate bone marrow cells from C57BL6/J mice, femora and tibiae were aseptically removed after sacrifice. The epiphyses of these long bones were removed, and the bone marrow was flushed into a sterile Petri dish with a 25-gauge needle and $10 \mathrm{ml}$ syringe filled with culture medium. The bone marrow was then filtered with a $40 \mu \mathrm{m}$ nylon cell strainer (Falcon, USA) and centrifuged. The harvested cells were incubated in a culture medium comprising alphamodified minimal essential medium ( $\alpha$-MEM; Sigma) containing $10 \%$ fetal bovine serum (FBS), $100 \mathrm{IU} / \mathrm{ml}$ penicillin G (Meiji Seika, Tokyo, Japan), and $100 \mu \mathrm{g} / \mathrm{ml}$ streptomycin (Meiji Seika), with M-CSF added. Nonadherent cells were removed by washing with PBS, and adherent cells were harvested using trypsin-EDTA solution (Sigma-Aldrich). The harvested cells were seeded and further cultured in the presence of M-CSF. Adherent cells were used as osteoclast precursors in this study as previously reported [43]. Osteoclast precursors were seeded at $5 \times 10^{4}$ cells per $200 \mu \mathrm{l}$ of medium in a 96-well plate and cultured in medium containing M-CSF alone (100 ng/ml), M-CSF (100 ng/ml) and RANKL (100 ng/ $\mathrm{ml})$ or TNF- $\alpha(100 \mathrm{ng} / \mathrm{ml}), \mathrm{M}-\mathrm{CSF}(100 \mathrm{ng} / \mathrm{ml})$ and RANKL $(100 \mathrm{ng} / \mathrm{ml})$ or TNF- $\alpha(100 \mathrm{ng} / \mathrm{ml})$ with exendin-4 (100 ng/ $\mathrm{ml})$, and M-CSF $(100 \mathrm{ng} / \mathrm{ml})$ with exendin-4 $(100 \mathrm{ng} / \mathrm{ml})$, for 5 days. The cultured cells were then fixed with $10 \%$ formalin for $30 \mathrm{~min}$. After fixation, the cells were permeabilized with $0.2 \%$ Triton $\mathrm{X}-100$ for $5 \mathrm{~min}$ at room temperature, then incubated in TRAP staining solution prepared as described above. TRAP-positive cells with three or more nuclei were considered to be osteoclasts and were counted under a light microscope.

2.4. Preparation of Bone Marrow Stromal Cells. Bone marrow cells were obtained by the method described above and cultured in Dulbecco's modified Eagle's medium (DMEM; Sigma) containing $10 \% \mathrm{FBS}, 100 \mathrm{IU} / \mathrm{ml}$ penicillin G (Life Technologies, Carlsbad, CA), and $100 \mu \mathrm{g} / \mathrm{ml}$ streptomycin (Life Technologies) for two weeks. Then the culture disks were washed vigorously with PBS to remove nonadherent 
cells. Adherent cells were used as stromal cells in this study as previously reported [43].

2.5. Isolation of Murine Macrophages. Macrophages were obtained from the peritoneal cavity of mice. To obtain resident macrophages under resting conditions, we injected $5 \mathrm{ml}$ of sterile ice-cold PBS ( $\mathrm{pH}$ 7.4) into the peritoneal cavity and aspirated the fluid to harvest peritoneal cells. The cells were washed twice with $\alpha$-MEM medium (Sigma) containing $10 \%$ FBS. After 1 hour of culture, nonadherent cells were removed, and after 24 hours of culture, adherent cells were harvested and used as macrophages.

2.6. Isolation of RNA and Real-Time RT-PCR Analysis. Calvariae from the in vivo experiments were frozen in liquid nitrogen and crushed by Micro Smash MS-100R (Tomy Seiko, Tokyo, Japan) in $800 \mu \mathrm{l}$ TRIzol reagent (Invitrogen, Carlsbad, CA) for each sample. Total RNA was extracted with an RNeasy mini kit (Qiagen, Valencia, CA) according to the manufacturer's protocol. For the in vitro experiments, bone marrow stromal cells or macrophages were incubated in culture medium supplemented with PBS, LPS (100 ng/ml), LPS $(100 \mathrm{ng} / \mathrm{ml})$ and exendin- $4(100 \mathrm{ng} / \mathrm{ml})$, and exendin-4 $(100 \mathrm{ng} / \mathrm{ml})$. After three days of culture, total RNA was isolated from adherent cells. Total RNA of stromal cells or peritoneal macrophages was isolated using an RNeasy mini kit (Qiagen). cDNA was synthesized for each sample from $2 \mu \mathrm{g}$ total RNA with oligo-dT primers (Invitrogen) and reverse transcriptase in a total volume of $20 \mu \mathrm{l}$. The corresponding expression levels of RANKL and TNF- $\alpha$ mRNA were evaluated by real-time RT-PCR using a Thermal Cycler Dice Real Time System (Takara, Shiga, Japan). Each reaction comprised a total volume of $25 \mu \mathrm{l}$ containing $2 \mu \mathrm{l} \mathrm{cDNA}$ and $23 \mu \mathrm{l}$ of a mixture of SYBR Premix Ex Taq (Takara) and $50 \mathrm{pmol} / \mu \mathrm{l}$ primers. The PCR cycling conditions were as follows: $95^{\circ} \mathrm{C}$ for $10 \mathrm{~s}$ for initial denaturation followed by $45-60$ amplification cycles, with each cycle comprising a denaturation step of $95^{\circ} \mathrm{C}$ for $5 \mathrm{~s}$ and then an annealing step of $60^{\circ} \mathrm{C}$ for $30 \mathrm{~s}$. Relative expression levels of TNF- $\alpha$ and RANKL mRNAs were calculated by normalization to glyceraldehyde 3-phosphate dehydrogenase (GAPDH) mRNA levels. The primer sequences used for CDNA amplification were as follows: $5^{\prime}$-GGTGGAGCCAAAAGGGTCA- ${ }^{\prime}$ and $5^{\prime}$-GGGG GCTAAGCAGTTGGT- $3^{\prime}$ for GAPDH; $5^{\prime}$-AGGCGGTGC TTGTTCCTCA- $3^{\prime}$ and $5^{\prime}$-AGGCGAGAAGATGATCTGA CTGCC- $3^{\prime}$ for TNF- $\alpha$; and $5^{\prime}$-CCTGAGGCCAGCCATTT$3^{\prime}$ and $5^{\prime}$-CTTGGCCCAGCCTCGAT- $3^{\prime}$ for RANKL as already reported [43].

2.7. Micro-CT Imaging and Analysis for Bone Destruction Area. We obtained mouse calvariae immediately after sacrifice. The calvariae were fixed in $4 \%$ PBS-buffered formaldehyde at $4^{\circ} \mathrm{C}$ for 3 days. To assess the bone resorption pits on the calvariae, samples were washed thoroughly with PBS and scanned with microfocus computed tomography (ScanXmate-E090, Comscan, Kanagawa, Japan). TRI/3DBON64 software (RATOC System Engineering, Tokyo, Japan) was used to create three-dimensional images of the mouse calvariae, and the ratio of bone resorption area to total area was measured by ImageJ (NIH, Bethesda, MD) as previously reported [43].

2.8. Measurement of Serum CTX (C-Terminal Cross-Linked Telopeptide of Type I Collagen) Value. Blood was collected with microhematocrit tubes from the orbital sinuses of the mice after 5 days of daily administration of PBS, LPS with or without exendin-4, or exendin-4 alone. The levels of CTX were determined using a mouse C-terminal telopeptide of type I collagen assay kit (IDS, Tyne and Wear, UK). Levels of C-terminal telopeptide of type I collagen were assessed by measuring absorbance at $450 \mathrm{~nm}$ with a microplate reader (Remote Sunrise; Tecan, Japan), with $620 \mathrm{~nm}$ as the reference wavelength.

2.9. Cell Viability Assay for Osteoclast Precursors. Osteoclast precursors were seeded in a 96-well plate $\left(1 \times 10^{4}\right.$ cells in $200 \mu \mathrm{l}$ medium per well) and incubated with M-CSF $(100 \mathrm{ng} / \mathrm{ml})$ with or without exendin-4 $(100 \mathrm{ng} / \mathrm{ml})$. After 5 days of incubation, the cells were washed with PBS and cultured in $100 \mu \mathrm{l}$ culture medium of each well. Four replicates were assessed for each sample. Then, $10 \mu \mathrm{l}$ cell counting kit8 (Dojin, Kumamoto, Japan) solution was added to each well, and the plate was further incubated for $2 \mathrm{~h}$ at $37^{\circ} \mathrm{C}$. Absorbance at $450 \mathrm{~nm}$ was measured by a microplate reader for each well as previously reported [43].

2.10. Statistical Analysis. Data are expressed as means \pm standard deviation. The statistical significance of differences between groups was determined by Scheffe's test. $P<0.05$ was considered significant.

\section{Results}

3.1. In Vivo Inhibitory Effect of Exendin-4 on LPS-Induced Osteoclast Formation. We injected LPS with or without exendin- 4 on mouse calvariae to analyze the effect of exendin-4 on LPS-induced osteoclast formation in vivo. After LPS administration for 5 consecutive days, many large multinucleated osteoclasts were observed within the suture mesenchyme in the histological sections. However, the mean number of osteoclasts was significantly lower in the LPSand exendin-4-coadministered group than in the group administered with LPS alone (Figures 1(a) and 1(b)).

3.2. In Vivo Inhibitory Effect of Exendin-4 on LPS-Induced Bone Resorption. The mouse calvariae were scanned with microfocus computed tomography, and the amount of bone resorption areas was compared between each group. Many bone destruction defects were noted in the LPS group. The ratio of the bone resorption area to the total area was significantly higher in the LPS-administered group than in the PBS-administered and exendin-4-administered groups. Moreover, the LPS- and exendin-4-coadministered groups demonstrated less bone destruction than the group administered with LPS alone (Figures 2(a) and 2(b)). Serum levels of C-terminal telopeptide of type I collagen (CTX), a marker of bone resorption, in mouse serum samples were analyzed by a mouse CTX assay kit. The serum CTX level in the LPS-aloneadministered group was higher than PBS-administered 


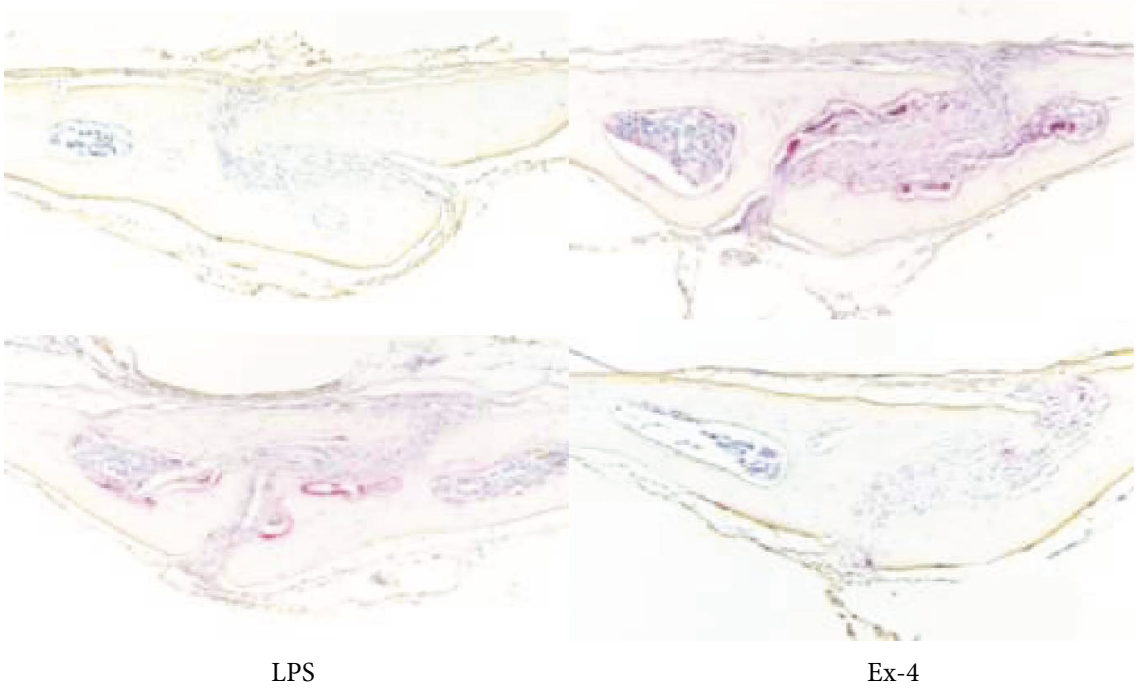

Ex-4

(a)

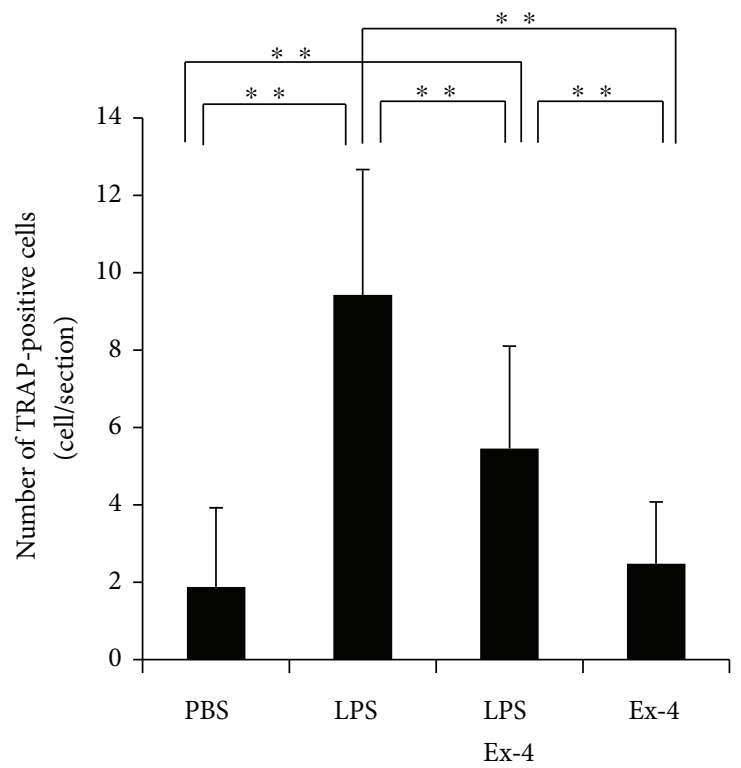

(b)

FIGURE 1: In vivo effect of exendin-4 on lipopolysaccharide- (LPS-) induced osteoclast formation. (a) Histological sections of mouse calvariae after 5-day daily supracalvarial injections with phosphate-buffered saline (PBS), LPS (100 $\mu \mathrm{g} /$ day), LPS (100 $\mu \mathrm{g} / \mathrm{day})$ with exendin-4 (20 $\mu \mathrm{g}$ / day), and exendin-4 (20 $\mathrm{g}$ /day). Tartrate-resistant acid phosphatase (TRAP) staining and hematoxylin counterstaining were performed. TRAP-positive cells were stained dark red. (b) The numbers of TRAP-positive cells in the suture mesenchyme of calvaria from the mouse groups administered with PBS, LPS, LPS with exendin-4, and exendin-4, respectively. Data is expressed as means \pm standard deviation (SD). Statistical significance were determined by Scheffe's test $\left(n=4 ;{ }^{* *} p<0.01\right)$.

group. However, the serum CTX level in the LPS- and exendin-4-coadministered group was lower than that in the LPS-alone-administered group (Figure 2(c)).

3.3. In Vivo Inhibitory Effect of Exendin-4 on the Expression of LPS-Induced Osteoclast-Related Cytokines (TNF- $\alpha$ and $R A N K L)$. Bone chips from mouse calvariae were analyzed by real-time RT-PCR to measure expression levels of TNF- $\alpha$ and RANKL mRNA. TNF- $\alpha$ and RANKL mRNA levels were elevated in the LPS-administered group compared with the PBS-administered group. Conversely, TNF- $\alpha$ and RANKL mRNA expression levels were reduced in the exendin-4and LPS-coadministered group compared with the LPSadministered group (Figure 3).

3.4. Exendin-4 Cannot Affect RANKL-Induced Osteoclast Formation, TNF- $\alpha$-Induced Osteoclast Formation, Cell Viability of Osteoclast Precursor Cells, and LPS-Induced 
PBS
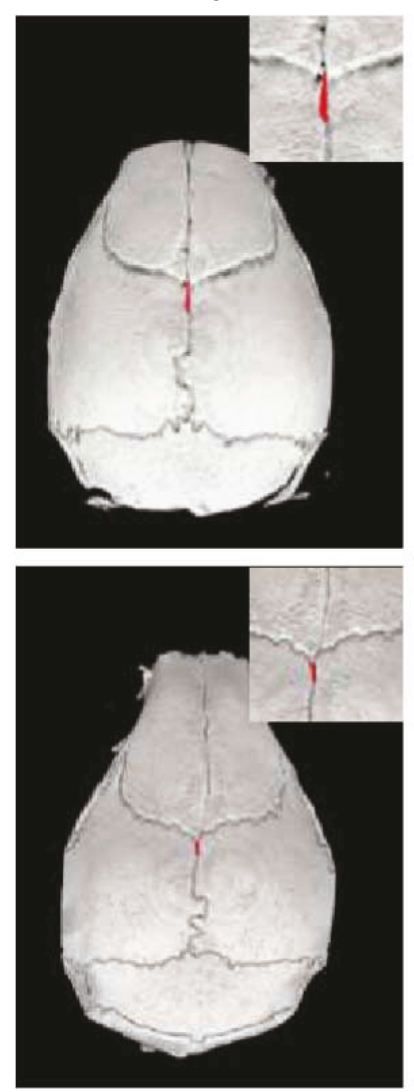

LPS

Ex-4

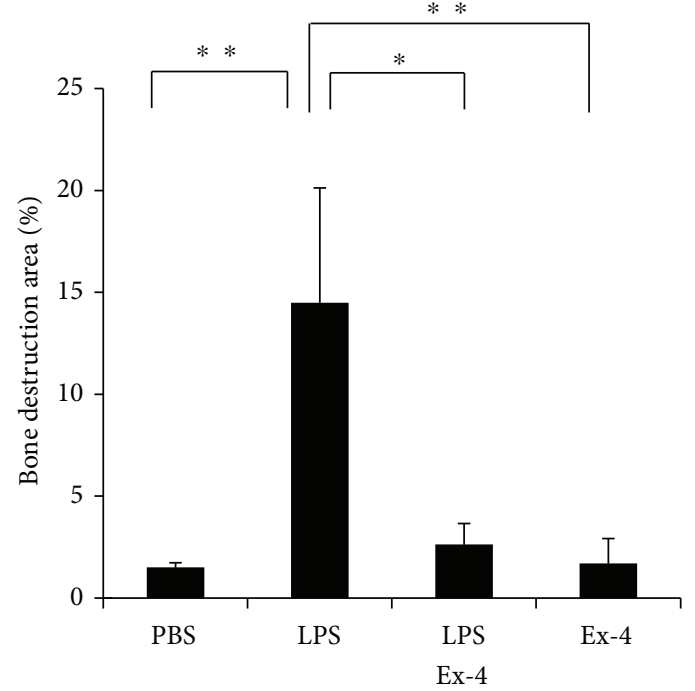

(b)
LPS
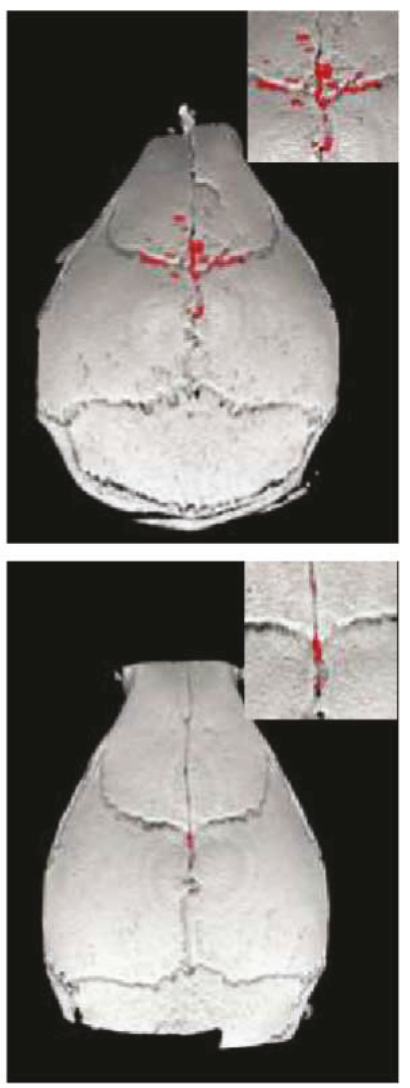

Ex-4

(a)

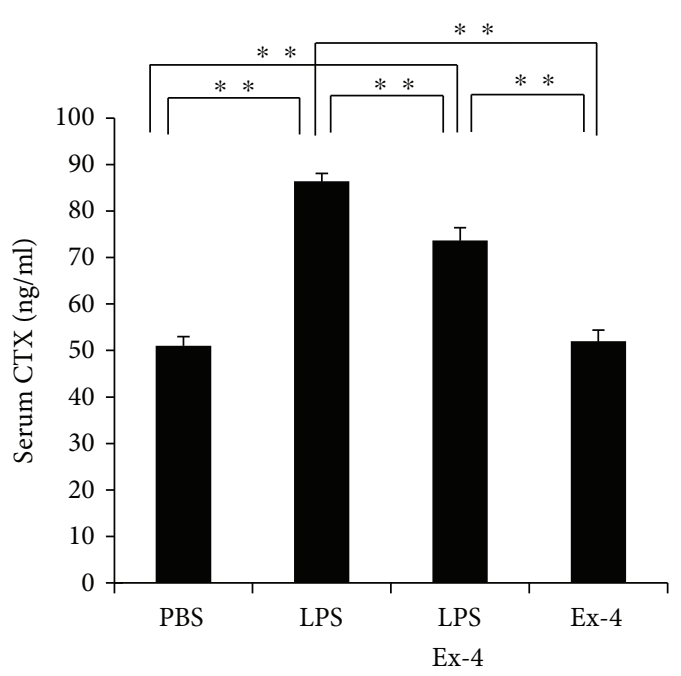

(c)

FIGURE 2: Exendin-4 inhibited LPS-induced bone resorption in vivo. (a) 3D reconstructed images of calvariae from micro-CT scanning. Mice were subjected to 5-day daily subcutaneous injections on the calvariae with PBS, LPS (100 $\mu \mathrm{g} /$ day) with or without exendin-4 (20 $\mu \mathrm{g} / \mathrm{day})$, and exendin-4 $(20 \mu \mathrm{g} / \mathrm{day})$, and calvariae were excised on the sixth day. The red dots indicate areas of bony destruction. (b) Ratio of bone destruction area to total bone area. Data is expressed as means $\pm \operatorname{SD}\left(n=4 ;{ }^{*} p<0.05,{ }^{* *} p<0.01\right)$. The statistical significance of differences was determined by Scheffe's test. (c) Serum levels of C-terminal telopeptide of type I collagen (CTX) determined by a mouse CTX assay kit. Data is expressed as means \pm SD. The statistical significance of differences was determined using Scheffe's test $\left(n=4 ;{ }^{* *} p<0.01\right)$. 


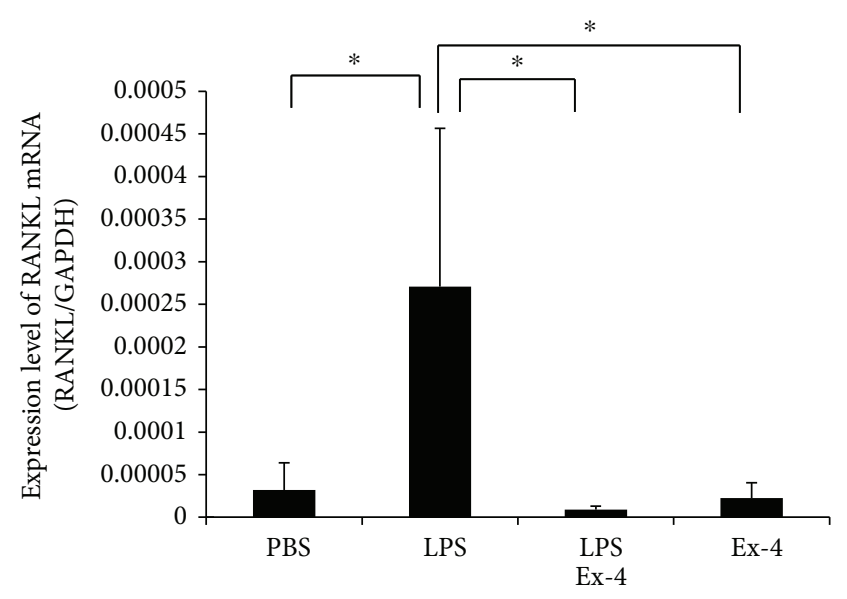

(a)

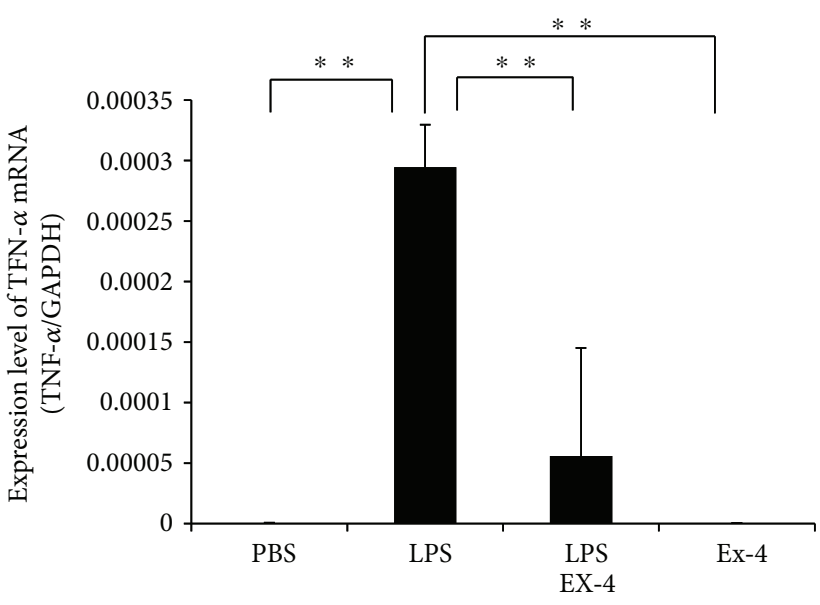

(b)

FIGURE 3: Exendin-4 suppressed expression of LPS-induced tumor necrosis factor- (TNF-) $\alpha$ and receptor activator of NF-kB ligand (RANKL) in vivo. TNF- $\alpha$ and RANKL mRNA levels in mouse calvariae were determined using real-time RT-PCR. Total RNA was isolated from mouse calvariae after 5-day daily supracalvarial injections with PBS, LPS (100 $\mu \mathrm{g} /$ day) with or without exendin-4 $(20 \mu \mathrm{g} /$ day), and exendin-4 alone $(20 \mu \mathrm{g} /$ day). TNF- $\alpha$ and RANKL mRNA levels were normalized to the expression of glyceraldehyde 3-phosphate dehydrogenase (GAPDH). Data is expressed as means \pm SD. The statistical significance of differences was determined using Scheffe's test $\left(n=4 ;{ }^{*} p<0.05,{ }^{* *} p<0.01\right)$.

RANKL Expression in Stromal Cells. To investigate whether exendin-4 affects osteoclast precursor cells directly, we analyzed the effects of exendin-4 on RANKL-induced osteoclast formation, TNF- $\alpha$-induced osteoclast formation, and viability of osteoclast precursors. There were large numbers of TRAP-positive cells among osteoclast precursor cells cultured with M-CSF and RANKL or TNF- $\alpha$. Likewise, TRAP-positive cells were also observed among the osteoclast precursor cells cultured with M-CSF and RANKL or TNF- $\alpha$ in the presence of exendin-4 (Figures 4(a) and 4(b)). Additionally, there was no evident difference in cell viability between the two cultures after 5 days of culture (Figure 4(c)). These results indicate that the inhibitory effect of exendin-4 may not be related to a direct action of exendin-4 on the proliferation and differentiation of osteoclast precursors.

We next evaluated whether exendin-4 inhibited LPSinduced RANKL expression in stromal cells in vitro. RANKL mRNA expression levels were higher in LPS-treated stromal cells than in control and exendin-4-treated stromal cells. However, stromal cells treated with both LPS and exendin4 demonstrated similar RANKL mRNA expression levels to those treated with LPS alone (Figure 4(d)). These results show that the inhibitory effect of exendin-4 may not be related to a direct action of exendin-4 on RANKL expression in stromal cells.

3.5. Exendin-4 Suppresses LPS-Induced TNF- $\alpha$ Expression in Macrophages. Real-time RT-PCR was performed to analyze TNF- $\alpha$ mRNA expression levels. TNF- $\alpha$ mRNA expression was elevated in macrophages treated with LPS alone compared with those treated with PBS. Conversely, TNF- $\alpha$ mRNA expression was inhibited in the exendin-4- and LPS-treated macrophages, compared with those treated with LPS alone (Figure 5).

\section{Discussion}

In the present study, we evaluated the effect of the GLP-1 receptor agonist exendin-4 on LPS-induced osteoclast formation and bone-resorption in vivo. We found that the GLP-1 receptor agonist inhibited LPS-induced osteoclast formation and bone resorption and also suppressed LPS-induced RANKL and TNF- $\alpha$ expression in vivo. Conversely, the GLP-1 receptor agonist did not directly inhibit RANKLinduced osteoclast formation, TNF- $\alpha$-induced osteoclast formation, osteoclast precursor cell viability, or LPS-induced RANKL expression in stromal cells in vitro. However, the GLP-1 receptor agonist inhibited LPS-induced TNF- $\alpha$ expression in macrophages in vitro.

GLP-1 plays a crucial role in blood glucose control. To simulate the effect of GLP-1, many GLP-1 analogues and GLP-1 receptor agonists have been developed. The amino acid sequence of the GLP-1 receptor agonist exendin- 4 is a modified version of the sequence of GLP-1. Exendin- 4 is resistant to degradation by dipeptidyl peptidase-IV and has a much longer plasma half-life than GLP-1 [40], which has a half-life of less than two minutes $[39,41]$. The extended half-life, improved pharmacokinetics, and high potency of exendin-4 make it suitable for clinical use $[39,40]$.

GLP-1 receptor-deficient mice have been reported to exhibit increased bone breakdown, which indicates that GLP-1 receptor signaling is essential to inhibition of osteoclast formation and bone resorption [31]. In the present study, exendin-4 inhibited LPS-induced osteoclast formation. Daily injections of $20 \mu \mathrm{g}$ of exendin- 4 for 5 days (a total of $100 \mu \mathrm{g}$ ) were sufficient to inhibit LPS-induced osteoclast formation in vivo. We also evaluated the inhibitory effect of exendin-4 on LPS-induced bone resorption. The extent of bone destruction was determined by the ratio of the destroyed bone area to total bone area, assessed by 

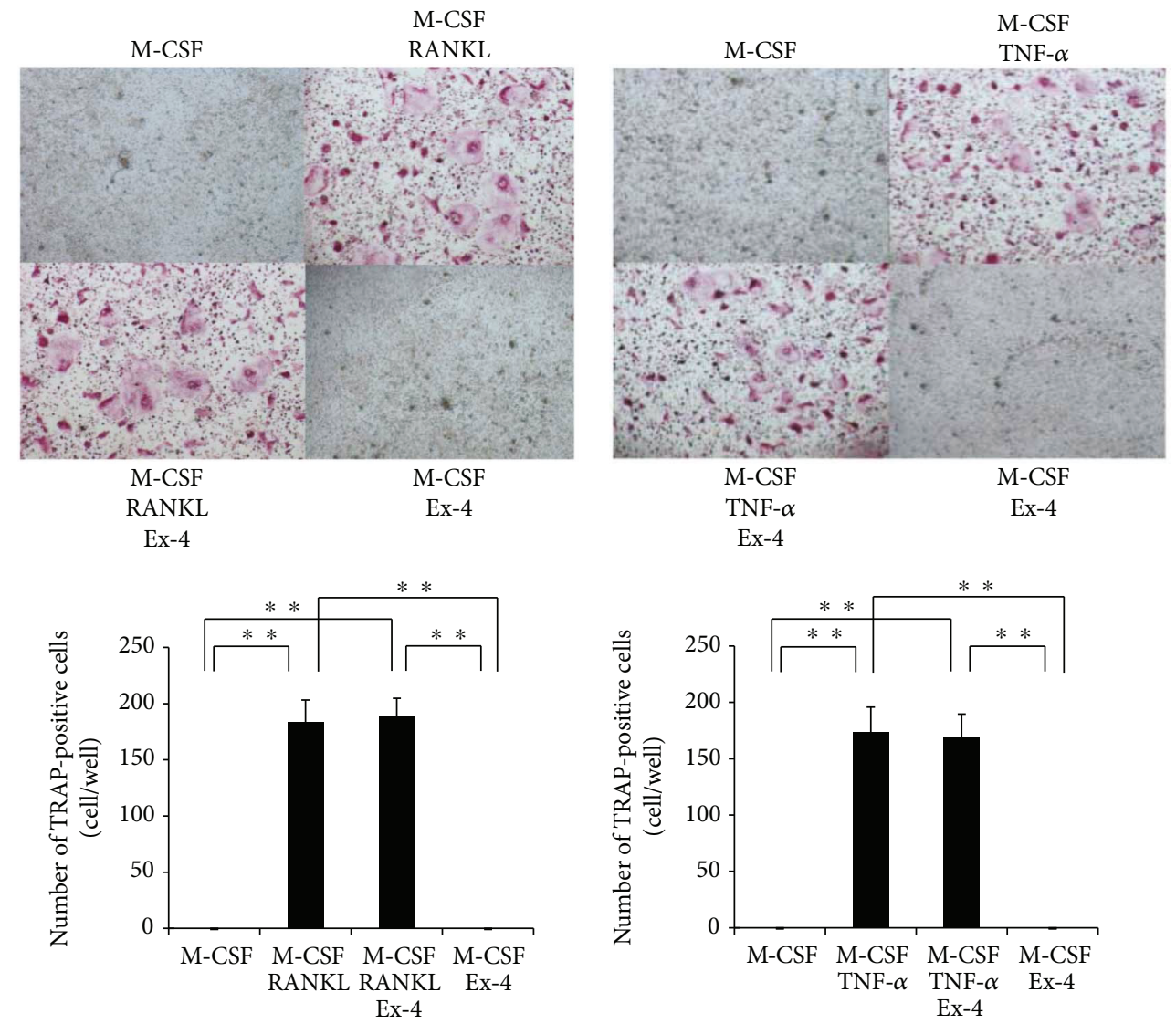

(a)

(b)

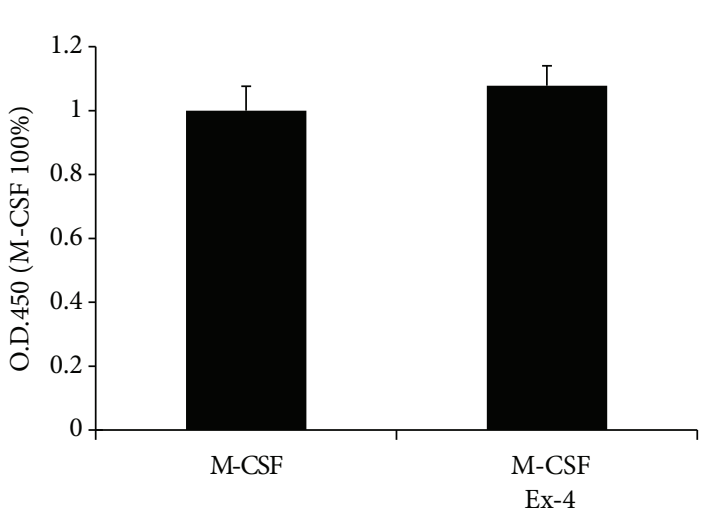

(c)

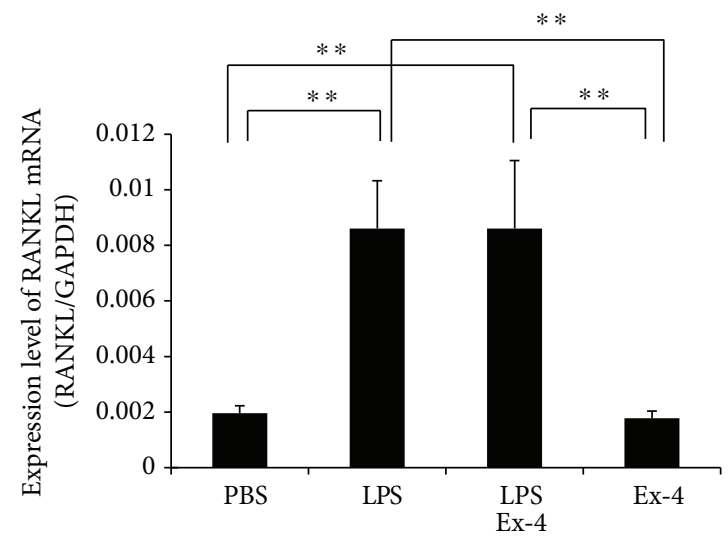

(d)

Figure 4: Exendin-4 had no effect on RANKL-induced osteoclast formation, TNF- $\alpha$-induced osteoclast formation, osteoclast precursor cell viability, or LPS-induced RANKL expression in stromal cells in vitro. (a) Microscopic images and numbers of TRAP-positive cells. Osteoclast precursors were treated with macrophage colony-stimulating factor (M-CSF) alone, M-CSF with RANKL, M-CSF with RANKL and exendin4 , and M-CSF with exendin-4 for 5 days, then stained with TRAP solution. (b) Microscopic images and numbers of TRAP-positive cells. Osteoclast precursors were treated with M-CSF alone, M-CSF with TNF- $\alpha$, M-CSF with TNF- $\alpha$ and exendin-4, and M-CSF with exendin4 for 5 days, then stained with TRAP solution. (c) Cell viability of osteoclast precursor cells treated with M-CSF alone and M-CSF with exendin- 4 for 5 days. Cell viability was determined by cell counting kit- 8 . Data is presented as percentage activity relative to the activity in the culture with M-CSF alone and is expressed as means \pm SD. (d) RANKL mRNA expression levels in stromal cells determined by realtime RT-PCR method. Total RNA was extracted from stromal cells that were cultured with PBS, LPS with or without exendin-4, and exendin-4 alone, respectively. RANKL mRNA levels were normalized to that of GAPDH. Statistical significance of differences was determined by Scheffe's test $\left(n=4 ;{ }^{* *} P<0.01\right)$. 


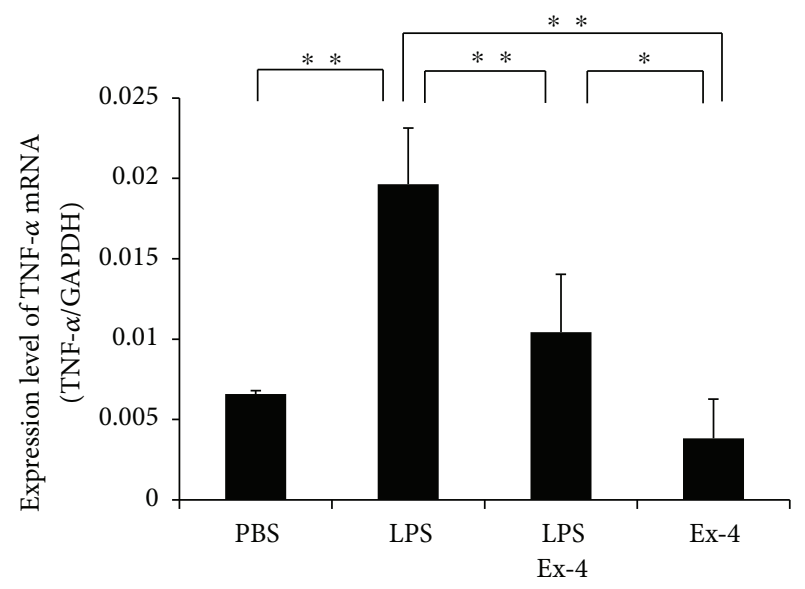

FIGURE 5: Exendin-4 inhibited LPS-induced expression of TNF- $\alpha$ in macrophages. TNF- $\alpha$ mRNA levels in macrophages were detected by real-time RT-PCR. Total RNA was isolated from macrophages cultured with PBS, LPS with or without exendin-4, and exendin-4 alone. TNF- $\alpha$ mRNA levels were normalized to the levels of GAPDH. Statistical significance of differences was determined by Scheffe's test $\left(n=4 ;{ }^{*} p<0.05,{ }^{* *} P<0.01\right)$.

microfocus computed tomography imaging, and by the serum CTX value of each experimental group. We found that the extent of bone destruction was significantly lower in the LPS- and exendin-4-coadministered group than the group administered with LPS alone. Our results suggest that exendin-4 inhibited LPS-induced osteoclast formation and bone resorption in vivo.

In this study, we administered $20 \mu \mathrm{g} /$ day exendin- 4 for 5 days, injected into the supracalvaria. Although previous rodent studies used $20 \mu \mathrm{g} / \mathrm{kg}$ exendin- 4 daily for 4 weeks $[41,44]$, we opted to use a higher dose to enhance the inhibitory effects of exendin-4. Further investigation using clinically relevant doses is needed.

Our findings prompted us to explore the mechanisms contributing to the inhibition of LPS-induced osteoclast formation and bone resorption. We considered two possible mechanisms. First, we considered whether exendin- 4 inhibited LPS-induced expression of inflammatory cytokines related to osteoclast formation, such as TNF- $\alpha$ and RANKL. Many studies have indicated that LPS induces TNF- $\alpha$ and RANKL in vivo $[28,45]$. RANKL is an essential cytokine for osteoclast formation [10], and it has been reported that TNF- $\alpha$ also can induce osteoclast formation in vivo $[15,16]$. Therefore, it is reasonable to suspect that if levels of both of these cytokines are decreased, osteoclast formation will be inhibited. In the present study, TNF- $\alpha$ and RANKL mRNA levels were elevated in the LPS-administered mice. However, this LPS-induced increase in TNF- $\alpha$ and RANKL mRNA levels was inhibited in the exendin-4- and LPS-coadministered group, compared with the group administered LPS only. This suggests that one of the mechanisms underlying the inhibitory effect of exendin-4 on LPS-induced osteoclast formation is the inhibition of LPS-induced osteoclast-related cytokines. The other mechanism that we considered was that exendin-4 directly inhibited RANKL- and TNF- $\alpha$-induced osteoclast formation. In the present study, we investigated whether exendin- 4 exerted its inhibitory effect on osteoclasts by directly acting on osteoclast precursors. However, exendin4 did not inhibit RANKL- or TNF- $\alpha$-induced differentiation of osteoclast precursor cells into osteoclasts. Moreover, we investigated whether exendin-4 inhibited osteoclast precursor cell viability. We observed no difference in cell viability between the two groups after 5 days of culture. These results suggest that the inhibitory effect of exendin- 4 on osteoclast formation is not due to a direct action of exendin- 4 on osteoclast precursors. We then evaluated whether exendin-4 inhibited LPS-induced RANKL expression in stromal cells. Exendin-4 also failed to inhibit LPS-induced RANKL expression in stromal cells. This indicates that inhibition of RANKL expression by exendin- 4 may not be due to a direct action of exendin- 4 on stromal cells. Finally, we evaluated whether exendin- 4 inhibited LPS-induced TNF- $\alpha$ expression in macrophages. In our study, exendin-4 inhibited LPS-induced TNF- $\alpha$ expression of macrophages. Because TNF- $\alpha$ induces osteoclast formation and promotes RANKL expression in stromal cells, our results suggest that the in vivo inhibition of LPS-induced osteoclast formation by exendin- 4 may be the result of inhibition of LPS-induced TNF- $\alpha$ expression in macrophages and subsequent suppression of RANKL expression in stromal cells.

\section{Conclusions}

In conclusion, our results suggested that exendin- 4 can inhibit LPS-induced osteoclast formation and bone resorption in vivo. The underlying mechanism may be related to its inhibition in the production of LPS-induced TNF- $\alpha$ in macrophages but not related to its direct effect on osteoclast precursors or RANKL expression in stromal cells.

\section{Conflicts of Interest}

The authors declare that there is no conflict of interest.

\section{Authors' Contributions}

Wei-Ren Shen contributed to conception, design, data acquisition, analysis, and interpretation and drafted the manuscript. Hideki Kitaura contributed to conception, design, data acquisition, data analysis, and interpretation and drafted and critically revised the manuscript. Keisuke Kimura, Masahiko Ishida, Haruki Sugisawa, Akiko Kishikawa, Kazuhiro Shima, Saika Ogawa, and Jiawei Qi contributed to data acquisition and data analysis and drafted the manuscript. All authors gave final approval and agree to be accountable for all aspects of the work.

\section{Acknowledgments}

This work was supported in part by JSPS KAKENHI from the Japan Society for the Promotion of Science (no. 16K11776 to Hideki Kitaura). 


\section{References}

[1] A. Moayeri, M. Mohamadpour, S. F. Mousavi, E. Shirzadpour, S. Mohamadpour, and M. Amraei, "Fracture risk in patients with type 2 diabetes mellitus and possible risk factors: a systematic review and meta-analysis," Therapeutics and Clinical Risk Management, vol. Volume 13, pp. 455-468, 2017.

[2] J. S. Walsh and T. Vilaca, "Obesity, type 2 diabetes and bone in adults," Calcified Tissue International, vol. 100, no. 5, pp. 528-535, 2017.

[3] A. Montagnani and S. Gonnelli, "Antidiabetic therapy effects on bone metabolism and fracture risk," Diabetes, Obesity \& Metabolism, vol. 15, no. 9, pp. 784-791, 2013.

[4] M. T. Bazelier, A. M. Gallagher, T. P. van Staa et al., "Use of thiazolidinediones and risk of osteoporotic fracture: disease or drugs?," Pharmacoepidemiology \& Drug Safety, vol. 21, no. 5, pp. 507-514, 2012.

[5] M. T. Bazelier, P. Vestergaard, A. M. Gallagher et al., "Risk of fracture with thiazolidinediones: disease or drugs?," Calcified Tissue International, vol. 90, no. 6, pp. 450-457, 2012.

[6] D. J. Betteridge, "Thiazolidinediones and fracture risk in patients with type 2 diabetes," Diabetic Medicine, vol. 28, no. 7, pp. 759-771, 2011.

[7] A. V. Schwartz, E. Vittinghoff, D. C. Bauer et al., "Association of BMD and FRAX score with risk of fracture in older adults with type 2 diabetes," JAMA, vol. 305, no. 21, pp. 2184-2192, 2011.

[8] P. Vestergaard, L. Rejnmark, and L. Mosekilde, "Relative fracture risk in patients with diabetes mellitus, and the impact of insulin and oral antidiabetic medication on relative fracture risk," Diabetologia, vol. 48, no. 7, pp. 1292-1299, 2005.

[9] K. Redlich, S. Hayer, R. Ricci et al., "Osteoclasts are essential for TNF- $\alpha$-mediated joint destruction," The Journal of Clinical Investigation, vol. 110, no. 10, pp. 1419-1427, 2002.

[10] S. L. Teitelbaum, "Bone resorption by osteoclasts," Science, vol. 289, no. 5484, pp. 1504-1508, 2000.

[11] S. L. Teitelbaum, "Osteoclasts: what do they do and how do they do it?" The American Journal of Pathology, vol. 170, no. 2, pp. 427-435, 2007.

[12] Y. Azuma, K. Kaji, R. Katogi, S. Takeshita, and A. Kudo, "Tumor necrosis factor- $\alpha$ induces differentiation of and bone resorption by osteoclasts," The Journal of Biological Chemistry, vol. 275, no. 7, pp. 4858-4864, 2000.

[13] K. Kobayashi, N. Takahashi, E. Jimi et al., "Tumor necrosis factor $\alpha$ stimulates osteoclast differentiation by a mechanism independent of the ODF/RANKL-RANK interaction," The Journal of Experimental Medicine, vol. 191, no. 2, pp. 275286, 2000.

[14] K. Fuller, C. Murphy, B. Kirstein, S. W. Fox, and T. J. Chambers, "TNF $\alpha$ potently activates osteoclasts, through a direct action independent of and strongly synergistic with RANKL," Endocrinology, vol. 143, no. 3, pp. 1108-1118, 2002.

[15] H. Kitaura, M. S. Sands, K. Aya et al., "Marrow stromal cells and osteoclast precursors differentially contribute to TNF- $\alpha$ induced osteoclastogenesis in vivo," The Journal of Immunology, vol. 173, no. 8, pp. 4838-4846, 2004.

[16] H. Kitaura, P. Zhou, H. J. Kim, D. V. Novack, F. P. Ross, and S. L. Teitelbaum, "M-CSF mediates TNF-induced inflammatory osteolysis," The Journal of Clinical Investigation, vol. 115, no. 12, pp. 3418-3427, 2005.
[17] P. Orcel, M. Feuga, J. Bielakoff, and M. C. De Vernejoul, "Local bone injections of LPS and M-CSF increase bone resorption by different pathways in vivo in rats," The American Journal of Physiology-Endocrinology and Metabolism, vol. 264, 3 Part 1, pp. E391-E397, 1993.

[18] Y. Abu-Amer, F. P. Ross, J. Edwards, and S. L. Teitelbaum, "Lipopolysaccharide-stimulated osteoclastogenesis is mediated by tumor necrosis factor via its P55 receptor," The Journal of Clinical Investigation, vol. 100, no. 6, pp. 1557-1565, 1997.

[19] Y. Sakuma, K. Tanaka, M. Suda et al., "Crucial involvement of the EP4 subtype of prostaglandin E receptor in osteoclast formation by proinflammatory cytokines and lipopolysaccharide," Journal of Bone and Mineral Research, vol. 15, no. 2, pp. 218-227, 2000.

[20] A. L. Dumitrescu, S. Abd-El-Aleem, B. Morales-Aza, and L. F. Donaldson, "A model of periodontitis in the rat: effect of lipopolysaccharide on bone resorption, osteoclast activity, and local peptidergic innervation," Journal of Clinical Periodontology, vol. 31, no. 8, pp. 596-603, 2004.

[21] Y. H. Chung, E. J. Chang, S. J. Kim et al., "Lipopolysaccharide from Prevotella nigrescens stimulates osteoclastogenesis in cocultures of bone marrow mononuclear cells and primary osteoblasts," Journal of Periodontal Research, vol. 41, no. 4, pp. 288-296, 2006.

[22] N. Bostanci, R. P. Allaker, G. N. Belibasakis et al., "Porphyromonas gingivalis antagonises Campylobacter rectus induced cytokine production by human monocytes," Cytokine, vol. 39, no. 2, pp. 147-156, 2007.

[23] H. Kitaura, K. Kimura, M. Ishida, H. Kohara, M. Yoshimatsu, and T. Takano-Yamamoto, "Immunological reaction in TNF- $\alpha$-mediated osteoclast formation and bone resorption in vitro and in vivo," Clinical \& Developmental Immunology, vol. 2013, article 181849, 8 pages, 2013.

[24] C. Y. Chiang, G. Kyritsis, D. T. Graves, and S. Amar, "Interleukin-1 and tumor necrosis factor activities partially account for calvarial bone resorption induced by local injection of lipopolysaccharide," Infection and Immunity, vol. 67, no. 8, pp. 4231-4236, 1999.

[25] W. Zou and Z. Bar-Shavit, "Dual modulation of osteoclast differentiation by lipopolysaccharide," Journal of Bone and Mineral Research, vol. 17, no. 7, pp. 1211-1218, 2002.

[26] G. P. Garlet, C. R. Cardoso, T. A. Silva et al., "Cytokine pattern determines the progression of experimental periodontal disease induced by Actinobacillus actinomycetemcomitans through the modulation of MMPs, RANKL, and their physiological inhibitors," Oral Microbiology and Immunology, vol. 21, no. 1, pp. 12-20, 2006.

[27] M. Mormann, M. Thederan, I. Nackchbandi, T. Giese, C. Wagner, and G. M. Hansch, "Lipopolysaccharides (LPS) induce the differentiation of human monocytes to osteoclasts in a tumour necrosis factor (TNF) $\alpha$-dependent manner: a link between infection and pathological bone resorption," Molecular Immunology, vol. 45, no. 12, pp. 3330-3337, 2008.

[28] T. Kikuchi, T. Matsuguchi, N. Tsuboi et al., "Gene expression of osteoclast differentiation factor is induced by lipopolysaccharide in mouse osteoblasts via Toll-like receptors," Journal of Immunology, vol. 166, no. 5, pp. 3574-3579, 2001.

[29] X. Ma, H. Hui, Z. Liu et al., "Poly-GLP-1, a novel long-lasting glucagon-like peptide-1 polymer, ameliorates hyperglycaemia by improving insulin sensitivity and increasing pancreatic beta-cell proliferation," Diabetes, Obesity \& Metabolism, vol. 11, no. 10, pp. 953-965, 2009. 
[30] J. J. Holst, “The physiology of glucagon-like peptide 1," Physiological Reviews, vol. 87, no. 4, pp. 1409-1439, 2007.

[31] C. Yamada, Y. Yamada, K. Tsukiyama et al., "The murine glucagon-like peptide-1 receptor is essential for control of bone resorption," Endocrinology, vol. 149, no. 2, pp. 574-579, 2008.

[32] B. Nuche-Berenguer, P. Moreno, S. Portal-Nunez, S. Dapia, P. Esbrit, and M. L. Villanueva-Penacarrillo, "Exendin-4 exerts osteogenic actions in insulin-resistant and type 2 diabetic states," Regulatory Peptides, vol. 159, no. 1-3, pp. 61-66, 2010.

[33] Y. K. Loke, S. Singh, and C. D. Furberg, "Long-term use of thiazolidinediones and fractures in type 2 diabetes: a metaanalysis," CMAJ, vol. 180, no. 1, pp. 32-39, 2009.

[34] R. E. Aubert, V. Herrera, W. Chen, S. M. Haffner, and M. Pendergrass, "Rosiglitazone and pioglitazone increase fracture risk in women and men with type 2 diabetes," Diabetes, Obesity \& Metabolism, vol. 12, no. 8, pp. 716-721, 2010.

[35] J. P. Bilezikian, R. G. Josse, R. Eastell et al., "Rosiglitazone decreases bone mineral density and increases bone turnover in postmenopausal women with type 2 diabetes mellitus," The Journal of Clinical Endocrinology \& Metabolism, vol. 98, no. 4, pp. 1519-1528, 2013.

[36] G. Mabilleau, A. Mieczkowska, and D. Chappard, "Use of glucagon-like peptide-1 receptor agonists and bone fractures: a meta-analysis of randomized clinical trials," Journal of Diabetes, vol. 6, no. 3, pp. 260-266, 2014.

[37] B. Nuche-Berenguer, P. Moreno, P. Esbrit et al., "Effect of GLP-1 treatment on bone turnover in normal, type 2 diabetic, and insulin-resistant states," Calcified Tissue International, vol. 84, no. 6, pp. 453-461, 2009.

[38] P. L. Brubaker, "Incretin-based therapies: mimetics versus protease inhibitors," Trends in Endocrinology \& Metabolism, vol. 18, no. 6, pp. 240-245, 2007.

[39] J. J. Meier, M. A. Nauck, D. Kranz et al., "Secretion, degradation, and elimination of glucagon-like peptide 1 and gastric inhibitory polypeptide in patients with chronic renal insufficiency and healthy control subjects," Diabetes, vol. 53, no. 3, pp. 654-662, 2004.

[40] L. L. Nielsen and A. D. Baron, "Pharmacology of exenatide (synthetic exendin-4) for the treatment of type 2 diabetes," Current Opinion in Investigational Drugs, vol. 4, no. 4, pp. 401-405, 2003.

[41] X. Ma, J. Meng, M. Jia et al., "Exendin-4, a glucagon-like peptide-1 receptor agonist, prevents osteopenia by promoting bone formation and suppressing bone resorption in aged ovariectomized rats," Journal of Bone and Mineral Research, vol. 28, no. 7, pp. 1641-1652, 2013.

[42] K. Kimura, H. Kitaura, T. Fujii, Z. W. Hakami, and T. TakanoYamamoto, "Anti-c-Fms antibody inhibits lipopolysaccharideinduced osteoclastogenesis in vivo," FEMS Immunology \& Medical Microbiology, vol. 64, no. 2, pp. 219-227, 2012.

[43] J. Saeed, H. Kitaura, K. Kimura et al., "IL-37 inhibits lipopolysaccharide-induced osteoclast formation and bone resorption in vivo," Immunology Letters, vol. 175, pp. 8-15, 2016.
[44] M. Pereira, J. Jeyabalan, C. S. Jorgensen et al., "Chronic administration of Glucagon-like peptide-1 receptor agonists improves trabecular bone mass and architecture in ovariectomised mice," Bone, vol. 81, pp. 459-467, 2015.

[45] N. Wada, H. Maeda, Y. Yoshimine, and A. Akamine, "Lipopolysaccharide stimulates expression of osteoprotegerin and receptor activator of NF-kappa B ligand in periodontal ligament fibroblasts through the induction of interleukin-1 beta and tumor necrosis factor-alpha," Bone, vol. 35, no. 3, pp. 629-635, 2004. 


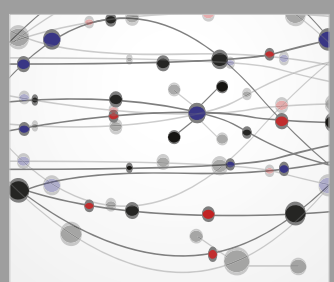

The Scientific World Journal
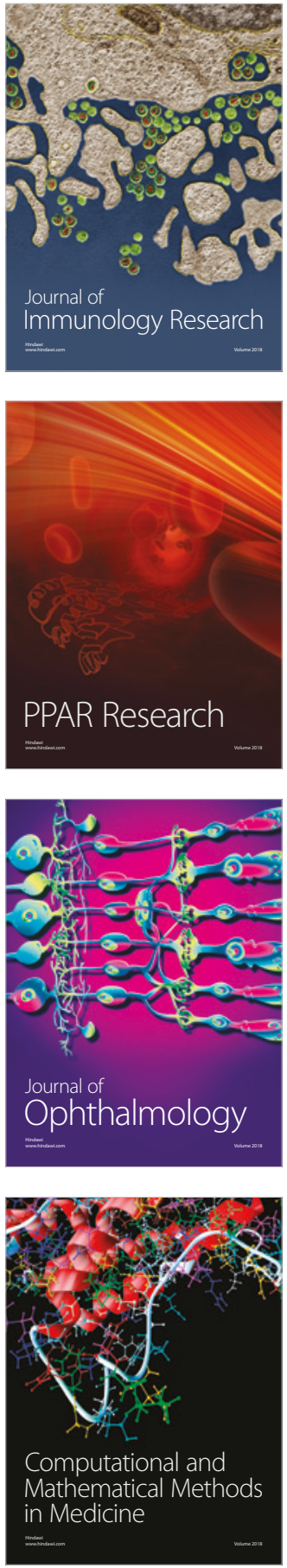

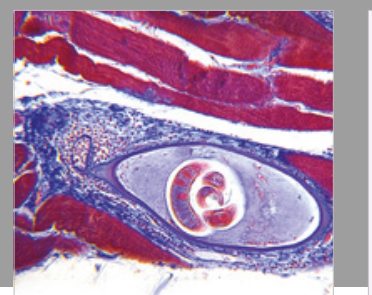

Gastroenterology Research and Practice

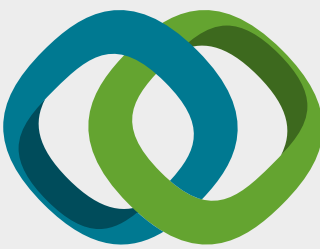

\section{Hindawi}

Submit your manuscripts at

www.hindawi.com
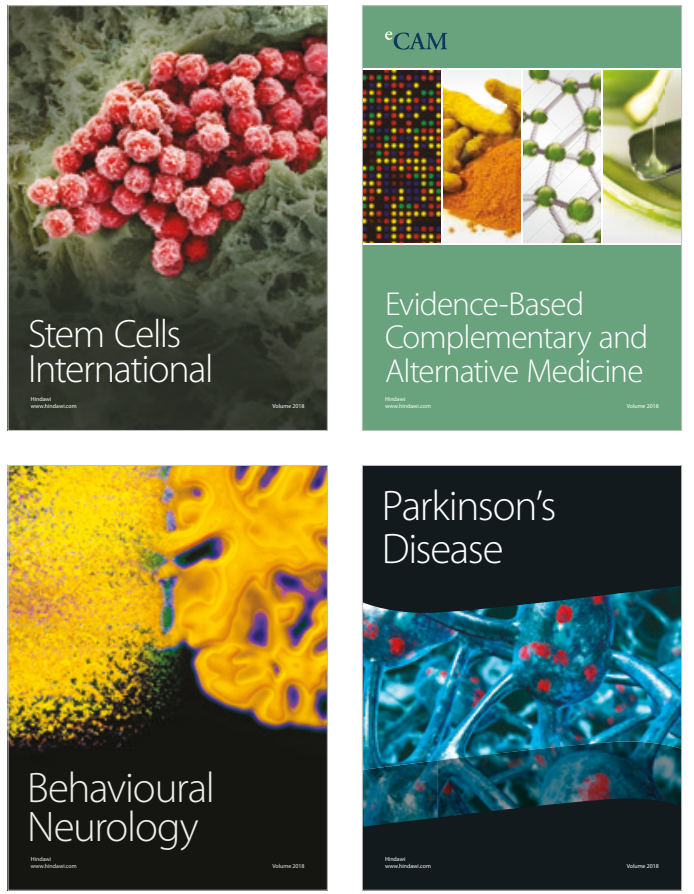

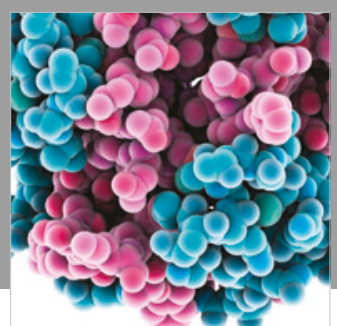

ournal of

Diabetes Research

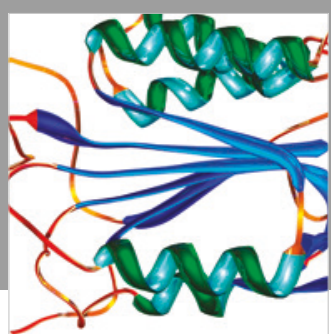

Disease Markers
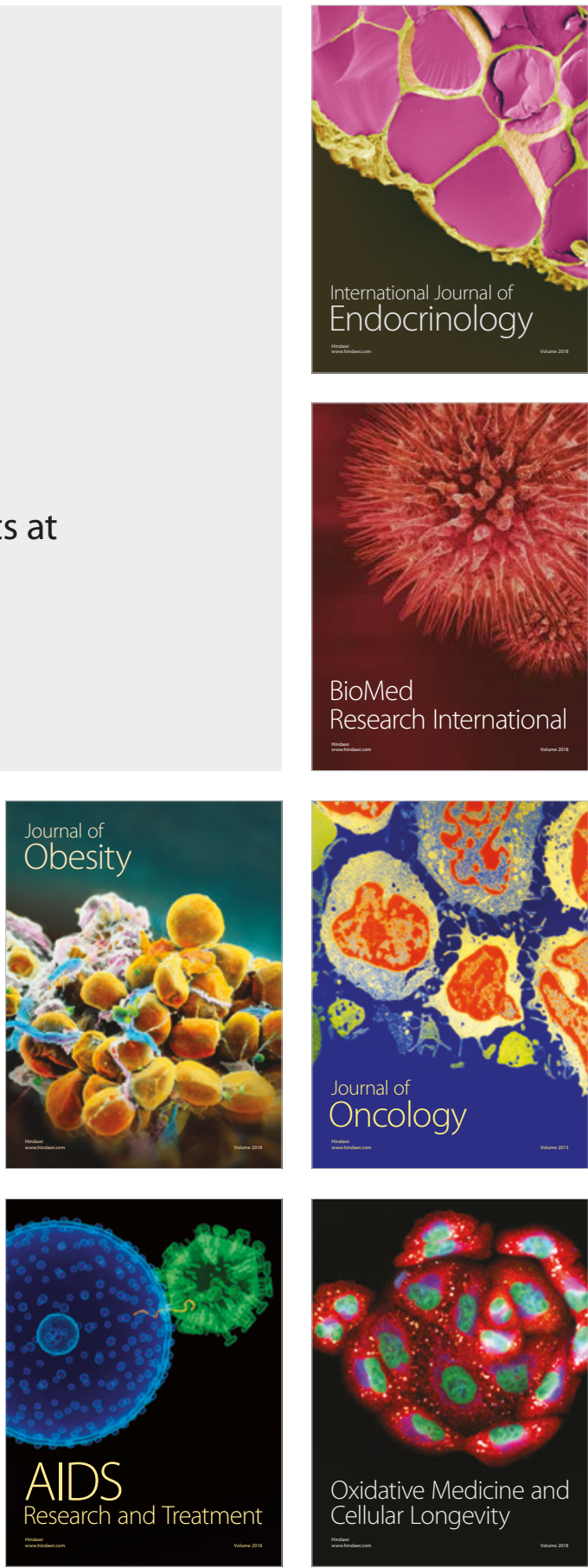